\title{
Neuropeptide alterations in the tree shrew hypothalamus during volatile anesthesia
}

\author{
Laetitia Fouillen ${ }^{1}$, Filomena Petruzziello, Julia Veit, Anwesha Bhattacharyya, Robert Kretz, \\ Gregor Rainer, Xiaozhe Zhang*
}

Visual Cognition Laboratory, Department of Medicine, University of Fribourg, Chemin du Musée 5, Fribourg, CH-1700, Switzerland

\begin{abstract}
Neuropeptides are critical signaling molecules, involved in the regulation of diverse physiological processes including energy metabolism, pain perception and brain cognitive state. Prolonged general anesthesia has an impact on many of these processes, but the regulation of peptides by general anesthetics is poorly understood. In this study, we present an in-depth characterization of the hypothalamic neuropeptides of the tree shrew during volatile isoflurane/nitrous oxide anesthesia administered accompanying a neurosurgical procedure. Using a predicted-peptide database and hybrid spectral analysis, we first identified 85 peptides from the tree shrew hypothalamus. Differential analysis was then performed between control and experimental group animals. The levels of 12 hypothalamic peptides were up-regulated following prolonged general anesthesia. Our study revealed for the first time that several neuropeptides, including alpha-neoendorphin and somatostatin-14, were altered during general anesthesia. Our study broadens the scope for the involvement of neuropeptides in volatile anesthesia regulation, opening the possibility for investigating the associated regulatory mechanisms.
\end{abstract}

\section{Introduction}

General anesthesia is characterized by several components such as hypnosis and analgesia [1], and is used during medical and experimental surgical procedures to reduce pain. An extensive literature suggests that both injection and inhalation general anesthetics exert their effects by acting on small molecule neurotransmitter and neuromodulators in the brain [2]. By binding to receptor proteins, general anesthetics can alter neuronal activity, change the basal extracellular levels of neurotransmitters, and generate various downstream effects. Among these downstream effects are changes in neuropeptide expression levels, which may importantly contribute to hypnotic and analgesic effects of general anesthetics [3].
Neuropeptides act as neuromodulators, tuning the efficacy of fast acting neurotransmitters, and are thought to be mostly released by volume transmission. A line of evidence has demonstrated that general anesthesia can evoke the extracellular release of neuropeptides and/or increasing the expression of neuropeptides intracellularly [4,5]. Opioid neuropeptides have been a major focus of investigation, with a number of studies showing that inhalation anesthetics, such as nitrous oxide or isoflurane, up-regulate the expression of a number of opiate neuropeptides, such as met-enkephalin and dynorphin [4,6-10]. These enhancements in opiate neuropeptides have been linked to the maintenance and reinforcement of certain aspects of general anesthesia induced by volatile anesthetics. Other work has examined the effects of exogenous neuropeptide applica-

\footnotetext{
* Corresponding author. Tel.: +41 263008910; fax: +41 263009734.

E-mail address: xiaozhe.zhang@unifr.ch (X. Zhang).

${ }^{1}$ Current address: Laboratoire de Biogenèse Membranaire, Université Bordefaux Ségalen, CNRS, UMR 5200, 33076 Bordeaux Cedex, France.
} 
tion on anesthesia. For example, somatostatin has been shown to induce general anesthesia. These studies enforce the presumed functional links between neuropeptides and general anesthesia. However, compared to well characterized influence of general anesthesia on small molecule neurotransmitters [2], we lack a comprehensive view on how general anesthesia alters the expression of various endogenous neuropeptides in the brain. Comprehensive characterization of the neuropeptidome during anesthesia can thus be useful to understand the involvement of neuropeptides to general anesthesia.

Neuropeptides are produced from protein precursors, stored in neurons and released into the extracellular space during activity of these neurons [12]. A single precursor can give rise to many neuropeptides but with distinct anesthetic properties [3]. Thus, selective and sensitive methods are needed for monitoring various individual neuropeptides with high accuracy and confidence. In the present study, we aim to characterize the effects of nitrous oxide and isoflurane, a combination of two commonly used inhalation anesthetics, on the hypothalamic neuropeptidome. The hypothalamus is a brain structure that is particularly rich in neuropeptides, and has previously been implicated in anesthesia [3]. We conducted our study in tree shrews (Tupaia belangeri), a non-rodent small mammalian species that is a close relative of primates and is considered to be a useful animal model for biomedical research [13].

We first sought to give a comprehensive identification of hypothalamic neuropeptidome of tree shrews. As no complete genome or proteome of tree shrews was available for database search, the identification of endogenous peptides in the tree shrew hypothalamus presented a challenge. To overcome this problem, we thus constructed a database of predicted peptides by performing in silico cleavage of neuropeptide precursors collected from species in Euarchontoglires clade (see Fig. 1A). Using a predicted peptide database allows the search to be redistricted to potential or known neuropeptides, avoiding the identification of peptide signal or polypeptides from the protein precursors. The construction of database for tree shrew peptide identification is possible because neuropeptides are highly conserved across species [14], and particularly for species closely related to tree shrews in the Euarchonta clade. We then identified endogenous peptides present in the tree shrew hypothalamus based on a hybrid de novo sequencing-guided MS/MS search engine coupled with our predicted-peptide database. We proceeded to compare differences in peptide expression levels between control tree shrews and the tree shrews subjected to isoflurane-nitrous oxide anesthesia, which was administered accompanying an experimental surgical procedure. Our study allows an in-depth characterization of the tree shrew hypothalamic peptidome, uncovering multiple peptides involved in general anesthesia.

\section{Material \& methods}

\subsection{Chemicals}

LC-MS grade acetonitrile and formic acid were purchased from Fisher Scientific (New Jersey, USA) and Fluka (Wisconsin, USA), respectively. Pure water was prepared by GenPure system (TKA, Niederelbert, Germany) Siliconized micro centrifuge tubes (2 $\mathrm{mL}$ ) were purchased from Eppendorf (Hamburg, Germany). Internal standard peptide ([D-Ala2]-Leucine enkephalin was purchased from Sigma Aldrich (Schnelldorf, Switzerland) Microcon centrifugal filter devices (Vivacon 500) were purchased from Sartorius AG (Goettingen, Germany Germany).

\subsection{Animals}

Tree shrew (T. belangeri) were used in the experiments. All animals were housed under constant temperature and humidity with free access to food and water. All procedures with live animals were conducted in accordance with the veterinary office of Fribourg, Switzerland. Three long-term anesthetized animals initially received Ketanarkon (ketamine, $100 \mathrm{mg} / \mathrm{kg}$, Streuli Pharma AG, Uznach, Switzerland) and
A

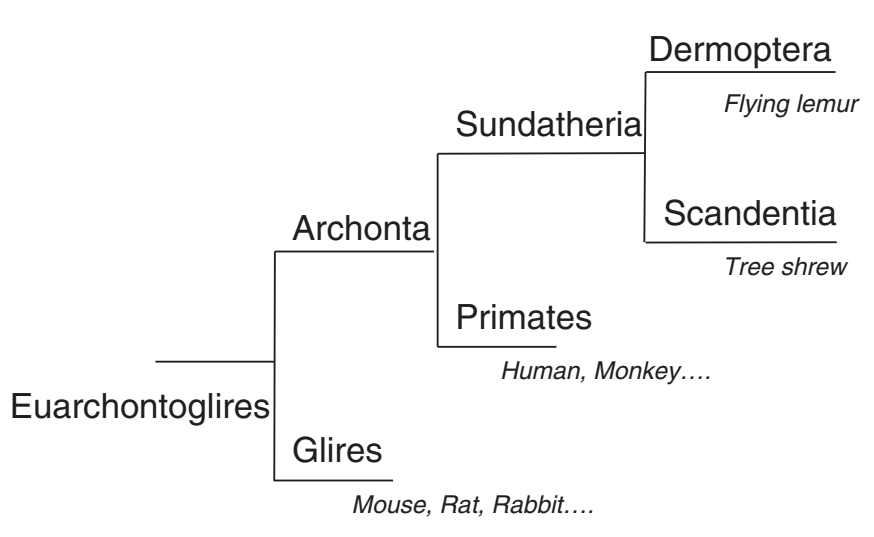

B

\section{Neuropeptides \\ Precursors}

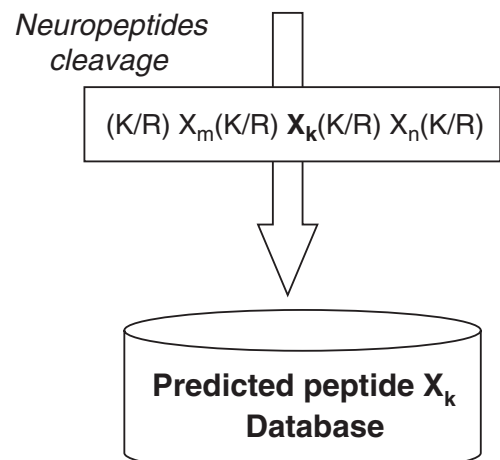

Fig. 1 - Phylogenic aspect and database construction. (A.) The phylogenic tree of the Euarchontoglires superorder shows the taxonomic proximity of tree shrews (Scandentia order) to the Primates and Glires orders. (B.) The predicted peptides database is constructed by processing the neuropeptide precursors following the neuropeptide cleavage rules. 
Atropine (Sintetica SA, Mendrisio, Switzerland) $(0.02 \mathrm{mg} / \mathrm{kg}$ ). The animals were artificially respirated at 100 strokes per minute (Harvard Instruments Respirator, Holliston, MA, USA) using a mixture of $70 \% \mathrm{~N}_{2} \mathrm{O}$ and $30 \%$ oxycarbon $\left(95 \% \mathrm{O}_{2} / 5 \% \mathrm{CO}_{2}\right)$ and isoflurane (Abbott Laboratories, Illinois, USA) (0.5\%-1.5\%) for a period of about twelve hours. At the beginning of this period, a small incision was made into the cranium and electrodes were advanced into the visual cortex for the study of electrophysiological responses to visual stimuli [15]. Three control animals were briefly anesthetized using Ketanarkon (ketamine, $100 \mathrm{mg} / \mathrm{kg}$, Streuli Pharma AG, Uznach, Switzerland) by s.c. injection. All animals were sacrificed by decapitation.

\subsection{Sample preparation}

The sample preparation is a crucial step in peptidomic experiments. Enzyme inactivation should be performed immediately post-sampling, otherwise protein degradation products would contaminate the sample and the endogenous peptides would be difficult or impossible to analyze. Following decapitation, the head was immediately heated up to $80^{\circ} \mathrm{C}$ in $16 \mathrm{~s}$ using microwave irradiation as described in Che et al. [16]. The brain was removed and stored at $-80^{\circ} \mathrm{C}$. Hypothalami were dissected from the denaturized brain.

The tissue is homogenized and peptides were extracted three times using a gradient of methanol solution. The first solution was $10 \%$ methanol (Fisher Scientific, Hampton, NH) with $0.2 \%$ formic acid, the second $30 \%$ methanol with $0.2 \%$ formic acid and the final $50 \%$ methanol with $0.2 \%$ formic acid, $15 \mu \mathrm{l}$ of total solvent was used per mg of tissue. Each time, the sample was homogenized by Precellys 24 homogenizer (Bertin Technologies, Montigny-le-Bretonneux, France) for $20 \mathrm{~s}$ twice. Each sample suspension was then centrifuged at 22,000 $\mathrm{g}$ for 60 min at $4{ }^{\circ} \mathrm{C}$ to remove insoluble material. The combination of all supernatants was transferred to a $10 \mathrm{kDa}$ cut-off spin column (Vivacon, Sartorius AG, Goettingen, Germany) after washing and centrifuged for $90 \mathrm{~min}$ at $14,000 \mathrm{~g}$ at $4{ }^{\circ} \mathrm{C}$ to exclude bigger peptides or small proteins.

\subsection{Qualitative LC-MS analysis}

The brain sample extracts were submitted to LC-Fourier Transformation (FT)-MS/MS for peptide identification. In each LC-FT-MS/MS analysis, $5 \mu \mathrm{l}$ extract was loaded on a $2.4 \mathrm{~cm}$ trap-column (100 $\mu \mathrm{m}$ inner diameter) for desalting. The trap column was packed in house with Reprosil-Pur C18 $5 \mu \mathrm{m}$ resin (Dr. Maisch GmbH, Ammerbuch-Entringen, Germany). The peptides were then separated by a 100-minute gradient on a $20 \mathrm{~cm}$ long Proxeon nanoESI emitter $(75 \mu \mathrm{m}$ inner diameter, $360 \mu \mathrm{m}$ outer diameter) packed in house with Reprosil-Pur C18 $3 \mu \mathrm{m}$ resin (Dr. Maisch GmbH, Ammerbuch-Entringen, Germany). The gradient started from 2 to $20 \% \mathrm{~B}$ during the first $12 \mathrm{~min}$, increased to $50 \% \mathrm{~B}$ in the next $68 \mathrm{~min}$, then was kept at 95\% B for $20 \mathrm{~min}$. Mobile phase A was $0.2 \%(\mathrm{v} / \mathrm{v})$ formic acid in water. Mobile phase B was 5\% (v/v) water and $0.2 \%(\mathrm{v} / \mathrm{v})$ formic acid in acetonitrile (Sigma-Aldrich Co, St Louis, MO). The flow rate was $300 \mathrm{nl} / \mathrm{min}$. The LC-MS analysis was performed on a hybrid linear ion trap and Orbitrap mass spectrometer (LTQ Discovery Orbitrap, Thermo Fisher, San Jose, CA, USA). The spray voltage was $1.5 \mathrm{kV}$, The capillary temperature of electrospray ionization
(ESI) source was $200^{\circ} \mathrm{C}$.Peptides were fragmented using a collision energy of 35 units and an activation time of $30 \mathrm{~ms}$. LCFT-MS/MS analysis was conducted using data-dependent acquisition in which the mass spectrometer automatically switches between a high resolution survey scan followed by consecutive CID fragmentation of the 5 most abundant multiply charged peptides eluting at this moment from the nano-LC column.

\subsection{Peptide identification \& database}

The database was constructed by first downloading a list of 2405 protein precursors $[17,18]$ from the Uniprot database (http:// www.uniprot.org/, 7 July 2010) restricted to Euarchontoglires species. All these sequences were then submitted to an in silico peptide cleavage using custom made software written in Perl, according to the following template: $(\mathrm{K} / \mathrm{R}) \mathrm{X}_{m}(\mathrm{~K} / \mathrm{R}) \mathrm{X}_{k}(\mathrm{~K} / \mathrm{R}) \mathrm{X}_{n}(\mathrm{~K} / \mathrm{R})$ where $\mathrm{X}$ is any amino acid, $m$ and $n$ correspond to $0,2,4,6$, and $k$ corresponds to $3-50$. The residues $X_{k}$ represent the predicted neuropeptide sequence. The predicted-peptide-database comprises the resulting sequences (50,377 entries).

Acquired MS/MS data were submitted to de novo sequencing using Peaks Studio software (v5.3, Bioinformatics Solutions, Inc., Waterloo, ON, Canada), with these parameters: enzyme (none), variable modifications (Amidation -0.98 Da, acetylation of lysine +42.01 Da, Pyro-glutamination from glutamic acid -18.01 Da and glutamine $-17.03 \mathrm{Da}$ ), mass values (monoisotopic); peptide mass tolerance (10 ppm), fragment mass tolerance (0.05 Da). Database interrogation was done with Peaks Protein ID using the same parameters as de novo sequencing and the custom-made predicted-peptide-database. Only peptides with a false discovery rate of less than $1 \%$ were considered. For the SPIDER similarity search, these additional settings were specified: homology match, fragment ion tolerance $0.05 \mathrm{Da}$, and Leucine equal to isoleucine.

Endogenous peptide fragmentation MS/MS spectra are more difficult to interpret than tryptic peptides, so all relevant hits were verified according to the following rules: The majority of the most intense MS/MS ions should belong either to the $y$ and $b$ products of the precursor peptide or have $a$ relevant link to these products, e.g., loss of $\mathrm{H}_{2} \mathrm{O}$ from an ion containing a serine residue; if present, the $\mathrm{y}$ ion originating from the fragmentation at the proline residue and the corresponding $\mathrm{b}$ ion should have increased intensity and at least three consecutive amino acids in the de novo sequencing has to be present [19].

\subsection{Peptide quantification}

Peptide differential analysis was conducted using the left hypothalami of six tree shrews (3 controls, 3 long-term anesthetized animals). The LC-FT-MS analysis of each hypothalamus sample was repeated 2 times for measuring the intensities of peptide precursors. Label-free peptide profiling was performed using SIEVE 1.3 (Service package 2, Thermo Scientific, San Jose, CA). SIEVE is a label-free differential analysis software that aligns and determines features across samples prepared from different conditions [20]. The following parameters were used in the peak alignment and frame generation: $\mathrm{m} / \mathrm{z} \min =300, \mathrm{~m} / \mathrm{z} \max =1500$, frame time width $=$ $6.0 \mathrm{~min}$, frame $\mathrm{m} / \mathrm{z}$ width $=0.02 \mathrm{Da}$, retention time start= 
Table 1 - Peptides identified in tree shrew hypothalamus. PTMS: Delta mass -17.03 Da, Pyro-Glu; Delta mass -0.98 Da, amidation; Delta mass -42.01 Da, acetylation. reflected the sequence identified by homology search. The number under the bracket $[\mathrm{X}-\mathrm{X}]$ indicates the fragmentation position of a neuropeptide.

\begin{tabular}{|c|c|c|c|c|c|c|c|c|}
\hline Precursor & $\begin{array}{l}\text { Uniprot } \\
\text { accession } \\
\text { number }\end{array}$ & Peptide name & Sequence & $\begin{array}{l}\text {-10lgP or } \\
\text { Spider } \\
\text { score }\end{array}$ & $\mathrm{M} / \mathrm{Z}$ & Z & $\mathrm{Mr}(\mathrm{Da})$ & $\begin{array}{l}\text { Mass } \\
\text { error } \\
(\mathrm{ppm})\end{array}$ \\
\hline Carboxypeptidase E & P16870 & WE-14 [1-11] & $\mathrm{Q}(-17.03)$ EPGAPAAGM & 35.7 & 456.200 & 2 & 910.400 & 0.8 \\
\hline Chromogranin-A & P10645 & & WSKMDQLAKEL & 41.45 & 450.235 & 3 & 1347.707 & -0.2 \\
\hline $\begin{array}{l}\text { Cocaine- and } \\
\text { amphetamine-regulated } \\
\text { transcript protein }\end{array}$ & P56388 & CART(55-102) & IPIYEKKYGQVPM & 37.02 & 522.618 & 3 & 1564.854 & 0.1 \\
\hline $\begin{array}{l}\text { Cocaine- and } \\
\text { amphetamine-regulated } \\
\text { transcript protein }\end{array}$ & P56388 & CART(1-52) [1-9] & Q(-17.03)EDAELQPR & 47.4 & 534.750 & 2 & 1067.501 & -0.9 \\
\hline Delta preprotachykinin I & Q9Z0K2 & & DAGHGQISHKMGYE & 62.01 & 510.564 & 3 & 1528.694 & -0.2 \\
\hline Delta preprotachykinin I & Q9Z0K2 & & DAGHGQISHKMGYERSAMQNYE & 74.03 & 837.038 & 3 & 2508.114 & 0.4 \\
\hline Amamide-related peptides & Q9WVA8 & Neuropeptide SF & SPAFLFQPQRF(-.98) & 44.19 & 668.860 & 2 & 1335.721 & -1.1 \\
\hline arma preprotachykinin & Q9Y494 & & $\mathrm{Q}(-17.03) I K E E L P E P F E H L L Q R I A$ & 60.5 & 725.058 & 3 & 2172.177 & -1.3 \\
\hline Garnma preprotachykinin I & Q9Z0K1 & & ALNSVGYE & 36.95 & 852.410 & 1 & 851.410 & 1.4 \\
\hline aDma preprotachykinin I & Q9Z0K1 & & ALNSVGYERSAMQNYE & 67.64 & 916.418 & 2 & 1830.836 & 0.9 \\
\hline Eluragon & P55095 & Glucagon-like peptide 1(7-36) & HAEGTFTSDVSSYLEGQAAKEFIAWLVKGR(-.98) & 84.05 & 824.923 & 4 & 3295.692 & 0.4 \\
\hline (1) Iroendocrine convertase 1 & P29120 & & SLDDDRVIWAEQQYQKERS & 46.5 & 789.391 & 3 & 2365.175 & 10.2 \\
\hline Neuropeptide Y & P68006 & Neuropeptide Y & YPSKPDNPGEDAPAEDMARYYSALRHYINLITRQRY(-.98) & 65.17 & 854.824 & 5 & 4269.121 & 0.8 \\
\hline Nefrosecretory protein VGF & 015240 & Neurosecretory protein VGF [562-593] & RAQEEAEAEERRLQEQEELENYIEHVLLRRP & 73.33 & 773.394 & 5 & 3861.972 & 0.8 \\
\hline Wrosecretory protein VGF & 015240 & Neurosecretory protein VGF [573-593] & RLQEQEELENYIEHVLLRRP & 62.68 & 641.844 & 4 & 2563.378 & -0.3 \\
\hline (e)rotensin/neuromedin $\mathrm{N}$ & Q9D3P9 & Neurotensin & Q(-17.03)LYENKPRRPYIL & 42.6 & 558.309 & 3 & 1671.927 & -2.6 \\
\hline rotensin/neuromedin $\mathrm{N}$ & Q9D3P9 & Neurotensin & QLYENKPRRPYIL & 41.09 & 423.241 & 4 & 1688.965 & 0.1 \\
\hline & O55241 & Orexin-B [1-12] & RPGPPGLQGRLQ & 36.3 & 425.914 & 3 & 1274.742 & -0.1 \\
\hline $\begin{array}{l}\text { Ritutary adenylate } \\
\text { cyclase-activating polypeptide }\end{array}$ & P18509 & PACAP 27 [16-27] & $\mathrm{Q}(-17.03) \mathrm{MAVKKYLAAVL}(-.98)$ & 47.79 & 658.891 & 2 & 1315.783 & 0 \\
\hline $\begin{array}{l}\text { able ATP-dependent RNA } \\
\text { case DDX41 }\end{array}$ & Q9UJV9 & & VRKLDEFLETGDLRTM* & 15.5 & 641.671 & 3 & 1922.0154 & 0.3 \\
\hline conkephalin-A & P01210 & PENK(143-183) [2-18] & $\mathrm{A}(+42.01)$ EEDDSLANSSDLLKEL & 53.75 & 945.949 & 2 & 1889.898 & 5.2 \\
\hline Proenkephalin-A & P01210 & Met-enkephalin-Arg-Phe [2-7] & GGFMRF & 43.31 & 357.673 & 2 & 713.347 & 2 \\
\hline Proenkephalin-A & P01210 & Peptide E & VGRPEWWMDYQKRYGGFL & 52.93 & 572.781 & 4 & 2287.125 & -1.5 \\
\hline Proenkephalin-A & P01210 & Peptide E (Frag) & PEWWMDYQ & 54.5 & 577.734 & 2 & 1153.469 & 0.8 \\
\hline Proenkephalin-A & P01210 & Peptide E (Frag) & RPEWWMDYQ & 52.91 & 655.784 & 2 & 1309.569 & 0.3 \\
\hline Proenkephalin-A & P01210 & Peptide E (Frag) & VGRPEWW(+15.99)MDYQ & 27.65 & 741.825 & 2 & 1481.651 & -1.7 \\
\hline Proenkephalin-A & P01210 & Peptide E (Frag) & VGRPEWWM & 42.93 & 530.754 & 2 & 1059.509 & -0.9 \\
\hline Proenkephalin-A & P01210 & Peptide E (Frag) & VGRPEWWMDY & 66.81 & 669.799 & 2 & 1337.599 & -1.2 \\
\hline Proenkephalin-A & P01210 & Peptide E (Frag) & VGRPEWWMDYQ & 59.77 & 733.829 & 2 & 1465.659 & 0.1 \\
\hline Proenkephalin-A & P01210 & Leu-enkephalin & YGGFL & 33.61 & 556.276 & 1 & 555.276 & -0.2 \\
\hline Proenkephalin-A & P01210 & Met-enkephalin & YGGFM & 35.12 & 574.234 & 1 & 573.234 & 1.9 \\
\hline Proenkephalin-A & P01210 & Met-enkephalin-Arg-Gly-Leu & YGGFM(+15.99)RGL & 49.63 & 458.720 & 2 & 915.441 & 0 \\
\hline Proenkephalin-A & P01210 & Met-enkephalin-Arg-Gly-Leu & YGGFMRGL & 52.46 & 450.724 & 2 & 899.448 & 1.8 \\
\hline Proenkephalin-A & P01210 & Met-enkephalin-Arg-Gly-Leu [2-8] & GGFMRGL & 44.17 & 369.192 & 2 & 736.384 & 1.2 \\
\hline Proenkephalin-A & P01210 & Met-enkephalin-Arg-Phe & YGGFM(+15.99)RF & 51.69 & 447.202 & 2 & 892.405 & 0.7 \\
\hline Proenkephalin-A & P01210 & Met-enkephalin-Arg-Phe & YGGFMRF & 49.82 & 439.204 & 2 & 876.409 & -0.6 \\
\hline
\end{tabular}


Dynorphin A [10-17]

Alpha-neoendorphin

47.07

P01148

P20382

Progonadoliberin-1

Gonadoliberin-1

Q(-17.03)HWSYGLRPG(-.98)

$\begin{array}{lll}514.779 & 2 & 1027.558\end{array}$

Gonadoliberin-1

EIGDEENSAKFPI $(-.98)$

HGLPLNLAIKPYLALKGSVA

Lipotropin gamma

Melanotropin alpha

Beta-endorphin [1-27]

P01194

Q9UHG2

Q9UHG2

Q9QXU9

Q9QXU9

Q9QXU9

Q9QXU9

Q9UHG2

Q9UHG2

Q9QXU9

P41540

P20366

P20366

P20366

P20396

Q8BL80

P16014

P16014

P16014

P16014

P16014

P16014

P16014

P16014

P13521

P13521

P13521

P13521

P13521

P47868

P47868

P47868

P05408

P05408

Q91ZM2

$\mathrm{P} 60041$

P60041

Somatostatin-14 [1-12]

P60041
Somatostatin-14

neurin $[7-24]$

[4-24]

Secretoneurin [13-24]

Secretoneurin [10-24]

Neuropeptide K [1-23]

ropeptide K [1-24]

Substance P

Somatostatin-28 [1-12]
DEGPYRMEHFRWGSPPKD

SYSMEHFRWGKPV(-.98)

YCGFMTSEKSQTPLVTLFKNAIIKNVH

YGGFMTSEKSQTPLVTLFKNAIIKNVHKKGQ

ALAHLLEAE

ALAHLLEAERQE

AVPRGEAAGAVQEL

AVPRGEAAGAVQELARALAHLLEAERQ

AVPRGEAAGAVQELARALAHLLEAERQE

GEAAGAVQELARALAHLLEAERQE

PPEGVLGALLRV

VLGALLRV

VMGQDLSECMPPEGVLGALLRV

AFLAPVASOLF*

DADSSIEKQVALLKALYGHGQIS

DADSSIEKOVALLKALYGHGOISH

KPQQFFGLM(-.98)

EEEYGVDEEEEEEAGECHEHC

PLQWKSSFRE*

DGVAELDQLLHY

DQLLHY

GVAELDQLLHY

Q(-17.03)YDGVAELDQL

Q(-17.03)YDGVAELDQLLH

Q(-17.03)YDGVAELDQLLHY(-.98)

QYDGVAELDQLLHY

YDGVAELDQLLHY

EQYTPQSLATLESVFQEL

IVEEOYTPOSLATLESVFOEL

SLATLESVFQEL

TPQSLATLESVFOEL

MOFPLMYEENSRDNPF

ELSAERPLNEQIAE

ELSAERPLNEQIAEAE

ELSAERPLNEQIAEAEAD

SVNPYLQGQRLDNVV

SVNPYLOGORLDNVVA

AGCKNFFWKTFT

AGCKNFFWKTFTSC

SANSNRAMAPRE
LNARAKPLDL $\begin{array}{lll}2 & 1227.691 & 0.2\end{array}$

$\begin{array}{llll}591792 & 2 & 1181.585 & -17\end{array}$

$\begin{array}{llll}724.356 & 2 & 1446.713 & -0.3\end{array}$

$\begin{array}{llll}692.417 & 3 & 2074.251 & -0.4\end{array}$

$\begin{array}{llll}735.337 & 3 & 2203.011 & -0.2\end{array}$

$\begin{array}{llll}541.602 & 3 & 1621.806 & 1.1\end{array}$

$\begin{array}{lll}4 & 3022.6 & -8\end{array}$

$\begin{array}{llll}578.314 & 6 & 3463.887 & -6.1\end{array}$

$\begin{array}{llll}483.766 & 2 & 965.533 & 0.8\end{array}$

$\begin{array}{llll}460.581 & 3 & 1378.745 & 2.6\end{array}$

$\begin{array}{llll}684.367 & 2 & 1366.734 & -0.3\end{array}$

$\begin{array}{llll}707.388 & 4 & 2825.554 & -0.3\end{array}$

$\begin{array}{llll}985.863 & 3 & 2954.589 & -0.3\end{array}$

$\begin{array}{llll}844.776 & 3 & 2531.330 & -0.3\end{array}$

$\begin{array}{llll}610.871 & 2 & 1219.743 & 0.1\end{array}$

$\begin{array}{llll}420.787 & 2 & 839.574 & 0.2\end{array}$

$\begin{array}{llll}772.061 & 3 & 2313.183 & 3.5\end{array}$

$\begin{array}{llll}582.328 & 2 & 1162.656 & 3.1\end{array}$

$\begin{array}{llll}815.100 & 3 & 2442.302 & 2.1\end{array}$

$\begin{array}{llll}645.840 & 4 & 2579.363 & 0.2\end{array}$

$\begin{array}{llll}547.794 & 2 & 1093.588 & 0.1\end{array}$

$\begin{array}{llll}1240.997 & 2 & 2479.994 & 0\end{array}$

$\begin{array}{llll}426.560 & 3 & 1276.682 & 3\end{array}$

$\begin{array}{llll}686.841 & 2 & 1371.682 & 0.4\end{array}$

$\begin{array}{llll}788.393 & 1 & 787.393 & 0.2\end{array}$

$\begin{array}{llll}629.328 & 2 & 1256.657 & 2.2\end{array}$

$\begin{array}{llll}617.285 & 2 & 1232.571 & 1\end{array}$

$\begin{array}{llll}742.356 & 2 & 1482.712 & -0.5\end{array}$

$\begin{array}{llll}823.399 & 2 & 1644.798 & 3.1\end{array}$

$\begin{array}{llll}832.402 & 2 & 1662.804 & 0.5\end{array}$

$\begin{array}{llll}768.371 & 2 & 1534.743 & -1.2\end{array}$

$\begin{array}{llll}1042.015 & 2 & 2082.030 & 0.1\end{array}$

$\begin{array}{llll}808.744 & 3 & 2423.232 & -0.2\end{array}$

$\begin{array}{llll}668.852 & 2 & 1335.705 & -1\end{array}$

$\begin{array}{llll}831.931 & 2 & 1661.863 & -1.2\end{array}$

$\begin{array}{llll}1009.440 & 2 & 2016.880 & -2.5\end{array}$

$\begin{array}{llll}799.905 & 2 & 1597.81 & 0.5\end{array}$

$\begin{array}{llll}899.941 & 2 & 1797.882 & -3.5\end{array}$

$\begin{array}{llll}992.976 & 2 & 1983.953 & 0.1\end{array}$

$\begin{array}{llll}851.449 & 2 & 1700.899 & 0.3\end{array}$

$\begin{array}{llll}886.968 & 2 & 1771.936 & 0\end{array}$

$\begin{array}{llll}555.834 & 2 & 1109.669 & -0.5\end{array}$

$\begin{array}{llll}725.354 & 2 & 1448.709 & 2.4\end{array}$

$\begin{array}{llll}820.374 & 2 & 1638.748 & 1\end{array}$

$\begin{array}{llll}622.787 & 2 & 1243.575 & -0.2\end{array}$ 
$15 \mathrm{~min}$, retention time stop $=85 \mathrm{~min}$, peak intensity threshold= 10,000 . Other parameters were set to the default values if they were not mentioned. The differential analysis of identified tree shrew peptides was conducted by loading their $\mathrm{m} / \mathrm{z}$ and retention time into Sieve as a seed file. The peptides with $\mathrm{S} / \mathrm{N}$ ratio higher than 10 and CV below 50\% were accepted for quantitative analysis. Two normalization methods were used in the label-free quantitation. Total ion current (TIC) normalization method was first used in the quantitative analysis. The peak intensities of peptides were then normalized to a spiked internal standard peptide [D-Ala2]-Leucine enkephalin (Spike normalization). A t-test was used for significance analysis (two-tailed distribution). The significance of the change was accepted for a peptide if a frame had a $p$-value of less than 0.05 in both normalization methods. The reported $p$-values and ratios of peptides given in the text represent the results processed using Spike normalization (see Supplementary Fig. S1 for the results regarding TIC normalization).

\section{Results}

Our study, with the purpose to identify and quantify endogenous hypothalamic peptides in the tree shrew hypothalamus, was conducted in three steps: i) custom-made predictedpeptide-database; ii) high accuracy LC-MS/MS data acquisition, and subsequent hybrid data interpretation by using de novo sequencing-guided search engine search or homology search; and iii) label-free quantification for investigating the influence of general anesthesia on the expression of hypothalamic peptides.

To construct the database, we first collected the sequences of known neuropeptide precursors from related species in the Euarchontoglires clade (see Fig. 1A), based on the list of reported neuropeptides, precursors and additional candidate $[17,18]$ (see Supplementary Table 1). Current studies showed that neuropeptides are produced from their precursors by different neuropeptide-processing enzymes in different pathways. Two main pathways, cysteine and subtilisin-like protease pathways, are known to be involved in cleavage mainly on dibasic sites, which can be separated by 0, 2, 4 or 6 amino acids $[21,22]$. The protein is submitted to in silico cleavage according to the following template: $(\mathrm{K} / \mathrm{R}) \mathrm{X}_{m}(\mathrm{~K} / \mathrm{R}) \mathrm{X}_{k}(\mathrm{~K} / \mathrm{R}) \mathrm{X}_{n}(\mathrm{~K} / \mathrm{R})$, where $\mathrm{X}$ is any amino acid, $m$ and $n$ correspond to $0,2,4,6$, and $k$ corresponds to $3-50$. The residues $X_{k}$ represent the predicted neuropeptide sequence $[23,24]$ (See the workflow presented in Fig. 1B). This predicted-peptide database, restricted to known or potential neuropeptide precursors of the Euarchontoglires clade, is available on our website (http://www.unifr.ch/inph/ vclab/home/internal/neuropep_euarglire).

Using de novo sequencing-guided peptide search software [25] on our database, we identified 75 peptides, which have a sequence strictly identical to one or more sequences in other species, with high confidence (FDR $\leq 1 \%$ ) (Table 1 and Supplementary Fig. 2). Fig. 2A represents the interpretation of the high accuracy MS/MS fragmentation spectrum at the precursor ions at $\mathrm{m} / \mathrm{z} 820.37\left([\mathrm{M}+2 \mathrm{H}]^{2+}\right)$. The search against our database assigned this sequence to somatostatin-14, corresponding to the amino acid string AGCKNFFWKTFTSC. The presence of this peptide in the database results from the cleavage of somatostatin precursor from four different species: Homo sapiens (Uniprot P61278), Macaca fascicularis (Uniprot P61279), Mus musculus (Uniprot P60041) and Rattus norvegicus (Uniprot P600429), underlining the highly conserved nature of somatostatin-14.

When de novo sequencing-guided peptide search did not yield a high confidence sequence for the MS/MS data, a homology search $[26,27]$ was conducted. This allowed us to identify a tree shrew peptide based on its sequence similarity to one or more peptides from other species in the database. Using this approach, we were able to identify ten additional peptides (homology search results in Table 1). Fig. 2B represents an example of a peptide identified using homology search, with a MS/MS fragmentation spectrum generated from the precursor ion at $\mathrm{m} / \mathrm{z} 426.56\left([\mathrm{M}+3 \mathrm{H}]^{3+}\right)$. De novo sequencing allowed us to unambiguously attribute the sequence PL/IQWKSSFRE to the MS/MS fragment spectrum, and subsequent homology search assigned the sequence to a peptide derived from the precursor Rho GTPase-activating protein 22. The alignment of other known Euarchontoglires sequences suggests that this peptide is not strictly identical between the different species. The major difference occurs at the $\mathrm{N}$-terminal of the peptide, as confirmed by the presence of the fragment ions $\mathrm{y}_{9}, \mathrm{y}_{8}, \mathrm{y}_{7}, \mathrm{~b}_{2}$ and $\mathrm{b}_{3}$. This tree shrew peptide starts with Pro-Leu-Gln, whereas the corresponding peptide in mouse (Glires order) starts with Pro-Val and the peptide of human (Primate order) starts with Pro-Ser. Our workflow allows the rapid identification of peptide sequences with amino acid residue insertion, mutation or deletion, which often occur between different species.

Having characterized the peptidome of the tree shrew hypothalamus, we further examined how nitrous oxideisoflurane induced anesthesia influenced the expression levels of hypothalamic peptides. We conducted a relative quantitative analysis on animals that received anesthesia for long term ( $12 \mathrm{~h}$ ) compared to controls animals. For quantitative analysis, a label-free quantification method was used to investigate the different levels of peptides in the hypothalamus in the presence or absence of anesthesia. We found that the levels of 12 peptides increased significantly during anesthesia (Fig. 3) using either TIC or Spike normalization data processing. Among these peptides, six peptides, including alphaneoendorphin and dynorphin A [AA10-17], are derived from proenkephalin A and B. One peptide was derived from the somatostatin precursor, and two peptides belonged to the protachykinin family. The other three significantly up-regulated peptides were derived from cocaine- and amphetamineregulated transcript protein, $\mathrm{SH} 2 \mathrm{~B}$ adapter protein 1, and neurotensin/neuromedin $\mathrm{N}$. The normalized ratios of these peptides comparing long-term anesthetized and control tree shrews ranged from 1.5 to 7.5 according to the Spike method. Somatostatin-14 showed a particularly large increase during anesthesia (normalized ratio $=7.46$ ).

\section{Discussion}

The extent to which neuropeptides are modulated by and contribute to general anesthesia is a topic of current research in anesthesiology. Here we examined how peptide levels in the hypothalamus are modulated by general anesthesia induced by 
A

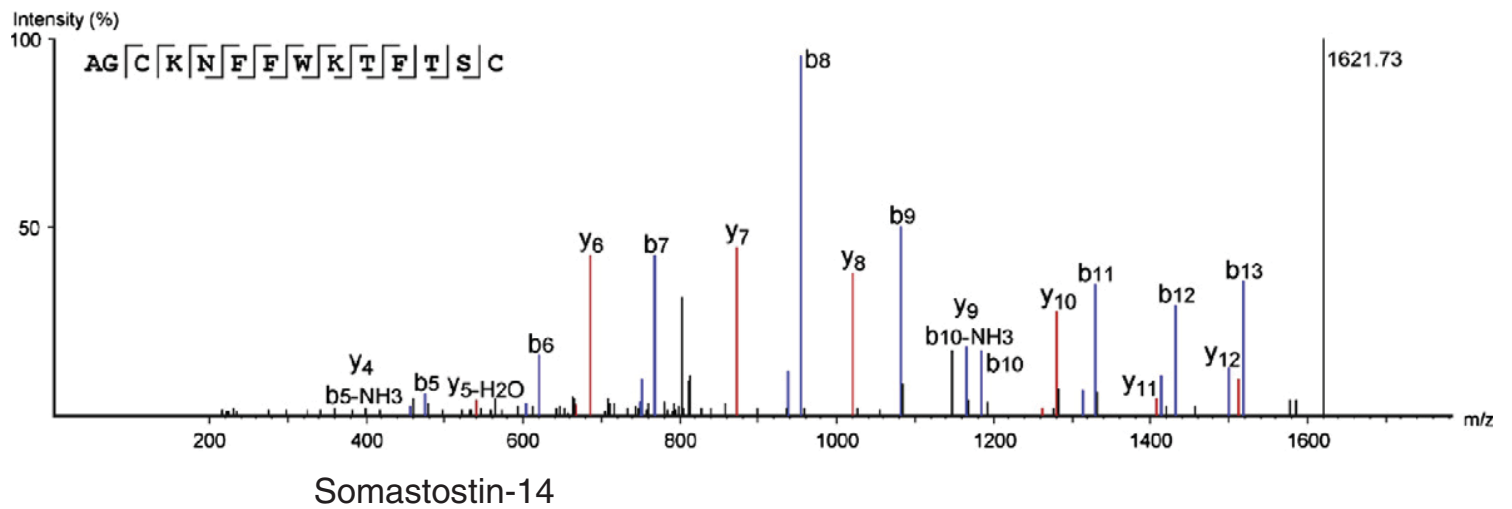

\section{AGCKNFFWKTFTSC [Tupaia belangeri] \\ AGCKNFFWKTFTSC [Homo sapiens] \\ AGCKNFFWKTFTSC [Mus Musculus]}

B

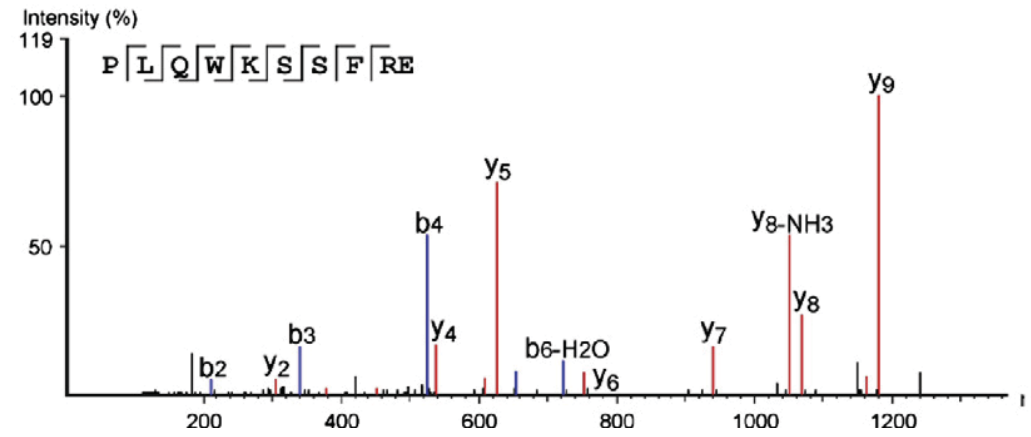

Rho GTPase-activating protein 22

$\begin{array}{ll}\text { PLQWKSSFRE } & \text { [Tupaia belangeri] } \\ \text { PV WKSSFRQ } & \text { [Homo sapiens] } \\ \text { PS WKSSFRQ } & \text { [Mus Musculus] }\end{array}$

Fig. 2 - Peptide identification (A.) The annotated MS/MS spectrum of the Somatostatin-14 peptide (AGCKNFFWKTFTSC, m/z 820.3743, $[\mathrm{M}+2 \mathrm{H}]^{2+}$ ) is presented. (B.) The alignment of the peptide sequence with the other Euarchontoglires Somatostatin-14 (Homo sapiens P61278, Mus musculus P60041) shows that they have an identical sequence. (C.) The annotated MS/MS spectrum of the peptide from Rho GTPase-activating protein 22. (PL/IQWKSSFRE, $\mathrm{m} / \mathrm{z} 426.5607,[\mathrm{M}+3 \mathrm{H}]^{3+}$ ) is presented. (D.) The alignment of the peptide sequence with the other Euarchontoglires sequences (Homo sapiens Q7Z5H3, Mus musculus Q8BL80) shows different sequences.

a combination of nitrous oxide and isoflurane in the tree shrew. Since there was no preexisting peptide database available for this species, we first constructed an appropriate database using data from closely related mammalian species. Using this database, we identified a total of 85 peptides in the tree shrew hypothalamus, including 29 neuropeptides. Of these, 12 peptides were significantly up-regulated during long-term general anesthesia that was administered accompanying a neurosurgical procedure.

Among the 12 up-regulated peptides, six were derived from opiate peptide precursors. A line of evidence has demonstrated that general anesthetics alter the levels of opioid peptides. For example, ketamine administration increases Leu-enkephalin release, while decreasing the release of Met-enkephalin [28]. Similarly, the application of isoflurane increases Leu-enkephalin expression in the hypothalamus [4]. Nitrous oxide has been strongly linked to neuropeptide release [3], with previous studies highlighting that the application of nitrous oxide evokes the release of several opiate peptides, such as enkephalins, $\beta$-endorphin [29] and dynorphin A and B. The nitrous-oxide induced neuropeptide changes can be quite large. For example, a cerebral spinal fluid (CSF) radioimmunoassay showed that exposure to nitrous oxide leads to a 400 -fold increase in Met-enkephalin [30]. Consistent with this is a previous study showing nitrous oxide induced elevations in tissue concentration of both Met-enkephalin and preproenkephalin hypothalamic mRNA levels [31]. In our study we observed a trend towards up-regulation of Met-enkephalin neuropeptide in the hypothalamus, which however did not reach significance $(p=$ 0.07). The elevation of Met-enkephalin in tree shrew hypothalamus was certainly less remarkable than that previously observed in CSF [30]. This difference may be due to the 


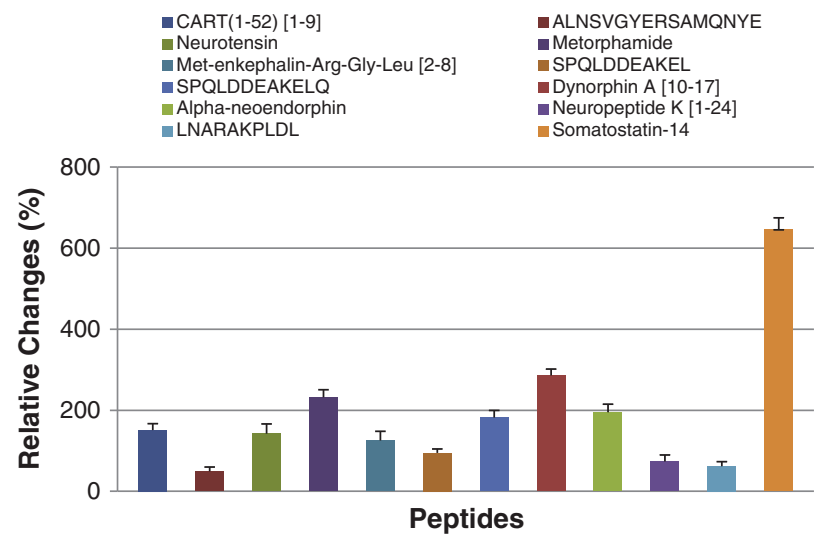

Fig. 3 - Significantly altered hypothalamic peptides during prolonged volatile anesthesia. Bars indicate the mean relative changes of peptides following prolonged anesthesia. Error bars indicate the variability of the difference between sample means (standard error). The significance level is $p<0.05$.

combinational use of nitrous oxide and isoflurane in our study rather than the use of nitrous oxide alone, or could be due to different media used for peptide measurement. In addition to a trend for Met-enkephalin, we observed significant increases in the levels of six other peptides derived from proenkephalin-A and proenkephalin-B, including metorphamide and alphaneoendorphin. These peptides, some of which are members of the classical opioid neuropeptide family, could play important roles in potentiating analgesia by acting on opioid receptors.

Our study revealed that general anesthesia applied during surgeric procedures leads to robust increases in the level of somatostatin-14. Somatostatin-14, which regulates the release of various neurotransmitters and other neuropeptides, has diverse effects such as control of body temperature, blood pressure and nociception [32]. Exogenously administrated somatostatin-14 acts as a potent analgesic [33], probably as a result of interaction with the opiate system. The elevation of endogenous somatostatin-14 observed in our study may consequently contribute to a reinforcement of general anesthesia. In addition to the changes of opiate and somatostatin peptides, we observed the elevation of several peptides derived from cocaineand amphetamine-regulated transcript protein, protachykinin1, SH2B adapter protein 1, gamma preprotachykinin I and neurotensin/neuromedin $\mathrm{N}$. There are no previous reports linking these identified peptides to anesthesia.

It should be noted that in practice general anesthesia accompanies surgical procedures, with general anesthetics being used to reduce awareness and pain. This was also the case in our study, where animals underwent electrode implantation in the visual cortex at the beginning of the anesthesia period. The surgery was performed in the occipital cortex, far away from the hypothalamus where brain samples were analyzed for peptide content. The surgery was brief, lasting only about $45 \mathrm{~min}$, occurred at the beginning of the anesthesia period around twelve hours prior to extraction of peptides, and also caused only minimal damage to the brain. In any case, our main findings on neuropeptide changes are largely consistent with current studies on the effects of general anesthetics administered in the absence of surgical procedures. We nevertheless feel that they provide an accurate picture of the practical influence of general anesthesia that is administered accompanying a medical or experimental surgical procedure.

Taken together, our results show that volatile anesthetics applied during surgery can generate a broad influence on the brain peptidergic system. We observed particularly pronounced effects on diverse members of the opioid family, as well as on levels of the somatostatin, preprotachykinin and neurotensin family peptides. The involvement of peptides derived from multiple prohormone families suggested differentiated pathways by which volatile anesthetics impact neuropeptide expression.

\section{Conclusion}

We have characterized the tree shrew hypothalamic neuropeptidome, using predicted-peptide database construction and hybrid spectral analysis. Our comparative analysis revealed that combined application of isoflurane and nitric oxide induces remarkable changes in a considerable number of peptides. Only some of these peptides had been previously associated with general anesthesia, so our findings broaden the scope of the involvement of various hypothalamic neuropeptides in general anesthesia, providing important medical values for evaluating the effects of general anesthesia on subjects.

Supplementary data to this article can be found online at http://dx.doi.org/10.1016/j.jprot.2012.11.002.

\section{Uncited reference}

\section{Acknowledgment}

This work was supported by the SNF R'Equip 316000-121308 and a EURYI award to GR.

\section{R E F E R E N C E S}

[1] Ishizawa Y. Mechanisms of anesthetic actions and the brain. J Anesth 2007;21:187-99.

[2] Muller CP, Pum ME, Amato D, Schuttler J, Huston JP, Silva MA. The in vivo neurochemistry of the brain during general anesthesia. J Neurochem 2011;119:419-46.

[3] Quock RM, Vaughn LK. Do inhalation general anesthetic drugs induce the neuronal release of endogenous opioid peptides? Life Sci 2005;77:2603-10.

[4] Chmielnicki Z, Was M, Kmieciak-Kolada K, Huzarska M, Spiewak $Z$, Pawlowski J, et al. Influence of isoflurane on enkephalin levels and on some indicatory enzymes in the central nervous system of rabbits. Pol J Pharmacol 1997;49:97-106.

[5] Grouzmann E, Borgeat A, Fathi M, Gaillard RC, Ravussin P. Plasma and cerebrospinal fluid concentration of neuropeptide $\mathrm{Y}$, serotonin, and catecholamines in patients under propofol or isoflurane anesthesia. Can J Physiol Pharmacol 2000;78:100-7.

[6] Cahill FJ, Ellenberger EA, Mueller JL, Tseng LF, Quock RM. Antagonism of nitrous oxide antinociception in mice by 
intrathecally administered antisera to endogenous opioid peptides. J Biomed Sci 2000;7:299-303.

[7] Branda EM, Ramza JT, Cahill FJ, Tseng LF, Quock RM. Role of brain dynorphin in nitrous oxide antinociception in mice. Pharmacol Biochem Behav 2000;65:217-21.

[8] Quock RM, Kouchich FJ, Tseng LF. Influence of nitrous oxide upon regional brain levels of methionine-enkephalin-like immunoreactivity in rats. Brain Res Bull 1986;16:321-3.

[9] Zuniga JR, Joseph SA, Knigge KM. The effects of nitrous oxide on the secretory activity of pro-opiomelanocortin peptides from basal hypothalamic cells attached to cytodex beads in a superfusion in vitro system. Brain Res 1987;420:66-72.

[10] Kmieciak-Kolada K, Chmielnicki Z, Was M, Huzarska M, Obuchowicz E, Spiewak Z, et al. Effect of enflurane on selected neuropeptides and marker enzymes in rabbit brain. Pol J Pharmacol 1998;50:315-25.

[11] Yasuda Y, Takeda A, Fukuda S, Suzuki H, Ishimoto M, Mori Y, et al. Orexin a elicits arousal electroencephalography without sympathetic cardiovascular activation in isoflurane-anesthetized rats. Anesth Analg 2003;97:1663-6.

[12] Hokfelt T, Broberger C, Xu ZQ, Sergeyev V, Ubink R, Diez M. Neuropeptides-an overview. Neuropharmacology 2000;39: 1337-56.

[13] Cao J, Yang EB, Su JJ, Li Y, Chow P. The tree shrews: adjuncts and alternatives to primates as models for biomedical research. J Med Primatol 2003;32:123-30.

[14] Hoyle $\mathrm{CH}$. Neuropeptide families: evolutionary perspectives. Regul Pept 1998;73:1-33.

[15] Veit J, Bhattacharyya A, Kretz R, Rainer G. Neural response dynamics of spiking and local field potential activity depend on CRT monitor refresh rate in the tree shrew primary visual cortex. J Neurophysiol 2011;106:2303-13.

[16] Che FY, Lim J, Pan H, Biswas R, Fricker LD. Quantitative neuropeptidomics of microwave-irradiated mouse brain and pituitary. Mol Cell Proteomics 2005;4:1391-405.

[17] Fricker LD. Analysis of mouse brain peptides using mass spectrometry-based peptidomics: implications for novel functions ranging from non-classical neuropeptides to microproteins. Mol Biosyst 2010;6:1355-65.

[18] Burbach JP. Neuropeptides from concept to online database. Eur J Pharmacol 2010;626:27-48 [www.neuropeptides.nl].

[19] Steen H, Mann M. The ABC's (and XYZ's) of peptide sequencing. Nat Rev Mol Cell Biol 2004;5:699-711.

[20] Mueller LN, Brusniak MY, Mani DR, Aebersold R. An assessment of software solutions for the analysis of mass spectrometry based quantitative proteomics data. J Proteome Res 2008;7: 51-61.

[21] Boonen K, Creemers JW, Schoofs L. Bioactive peptides, networks and systems biology. Bioessays 2009;31:300-14.
[22] Hook V, Funkelstein L, Lu D, Bark S, Wegrzyn J, Hwang SR. Proteases for processing proneuropeptides into peptide neurotransmitters and hormones. Annu Rev Pharmacol Toxicol 2008;48:393-423.

[23] Falth M, Skold K, Svensson M, Nilsson A, Fenyo D, Andren PE. Neuropeptidomics strategies for specific and sensitive identification of endogenous peptides. Mol Cell Proteomics 2007;6:1188-97.

[24] Rholam M, Fahy C. Processing of peptide and hormone precursors at the dibasic cleavage sites. Cell Mol Life Sci 2009;66:2075-91.

[25] Ma B, Zhang K, Hendrie C, Liang C, Li M, Doherty-Kirby A, et al. PEAKS: powerful software for peptide de novo sequencing by tandem mass spectrometry. Rapid Commun Mass Spectrom 2003;17:2337-42.

[26] Han Y, Ma B, Zhang K. SPIDER: software for protein identification from sequence tags with de novo sequencing error. J Bioinform Comput Biol 2005;3:697-716.

[27] Shevchenko A, Sunyaev S, Loboda A, Bork P, Ens W, Standing KG. Charting the proteomes of organisms with unsequenced genomes by MALDI-quadrupole time-of-flight mass spectrometry and BLAST homology searching. Anal Chem 2001;73:1917-26.

[28] Kolada I, Kmieciak-Kolada K, Huzarska M, Dyaczynska-Herman A, Herman ZS. Influence of ketamine and its interactions with morphine and nalbuphine on the level of enkephalins in some parts of the brain and spinal cord. Pol J Pharmacol 1994;46:139-46.

[29] Kugel G, Zive M, Agarwal RK, Beumer JR, Kumar AM. Effect of nitrous oxide on the concentrations of opioid peptides, substance $\mathrm{P}$, and LHRH in the brain and beta-endorphin in the pituitary. Anesth Prog 1991;38:206-11.

[30] Finck AD, Samaniego E, Ngai SH. Nitrous oxide selectively releases Met5-enkephalin and Met5-enkephalin-Arg6-Phe7 into canine third ventricular cerebrospinal fluid. Anesth Analg 1995;80:664-70.

[31] Agarwal RK, Kugel G, Karuri A, Gwosdow AR, Kumar MS. Effect of low and high doses of nitrous oxide on preproenkephalin mRNA and its peptide methionine enkephalin levels in the hypothalamus. Brain Res 1996;730: 47-51.

[32] Viollet C, Lepousez G, Loudes C, Videau C, Simon A, Epelbaum $\mathrm{J}$. Somatostatinergic systems in brain: networks and functions. Mol Cell Endocrinol 2008;286:75-87.

[33] Chrubasik J. Somatostatin. A review. Anasth Intensivther Notfallmed 1985;20:165-70. 